\title{
Impact of the Contributions of Glenn T. Seaborg on Nuclear Science
}

\author{
By Darleane C. Hoffman \\ Heavy Element Nuclear \& Radiochemistry Group, Nuclear Science Division, MS-70/319, Lawrence \\ Berkeley National Laboratory and Department of Chemistry, University of California, Berkeley, \\ CA 94720, and Seaborg Institute for Transactinium Isotopes, Lawrence Livermore National \\ Laboratory
}

(December 26, 2000)

Transuranium elements/Plutonium/Actinides/Transactinides/Seaborgium

\begin{abstract}
Glenn Theodore Seaborg (1912-199) was a world-renowned nuclear chemist, a Nobel Laureate in chemistry in 1951, co-discoverer of plutonium and nine other transuranium elements, Chairman of the U. S. Atomic Energy Commission from 1961-71, scientific advisor to ten U. S. presidents, active in national and international professional societies, an advocate for nuclear power as well as for a comprehensive nuclear test ban treaty, a prolific writer, an avid hiker, environmentalist, and sports enthusiast. He was known and esteemed not only by chemists and other scientists throughout the world, but also by lay people, politicians, statesmen, and students of all ages. This memorial includes a brief glimpse of Glenn Seaborg's early life and education, describes some of his major contributions to nuclear science over his long and fruitful career, and highlights the profound impact of his contributions on nuclear science, both in the U. S. and in the international community.
\end{abstract}

\section{l. Childhood and early education: 1912-1934}

In an attempt to place some of Glenn T. Seaborg's major accomplishments in perspective, I have divided his long and productive life into six major time periods as shown in Table 1.

Glen Theodore Seaborg was born on April 19, 1912 to Selma Olivia and Herman Theodore Seaborg in Ishpeming, Michigan, a small iron-mining town on the Upper Peninsula of Michigan, USA. His only sibling, Jeanette, was born two years later. A photo of Glen at 8 months old is shown in Fig. 1-1. His mother, Selma Olivia Eriksson (later changed to Erickson), was born in Grängesberg in the southern Dalarna region of Sweden, and came to Ishpeming in 1904, when she was 17 years old. Glen's father's parents had come from Sweden to Ishpeming in their youth and met and married there and his father was born in Ishpeming in 1880. Glen's parents met at a picnic on Swedish Midsummer's Day, June 24, 1908, and were married three years later on Swedish Midsummer's Day, June 24, 1911.

Since Glen's father was fluent in Swedish and it was his mother's native tongue, the Swedish language was spoken in the home and he learned to speak and understand Swedish 
before English. He started kindergarten in Ishpeming in September 1917. Glenn was nicknamed "Lanky" because he was so much taller than his classmates. The next photo (Fig. 1-2) shows him playing football with his friends near Mud Lake, Michigan in the Spring of 1922 when he was 10 years old.

Later that year, the family moved to Home Gardens, now a part of South Gate, near Los Angeles, California. A photo of Glenn and sister Jeanette taken about this time is shown in Fig. 1-3. (At this time he changed the spelling of his name from "Glen" to "Glenn".) This move to California was made primarily because his mother wanted to broaden her children's horizons beyond the limited opportunities available in Ishpeming. But Glenn Seaborg never forgot his roots in Ishpeming and was always very proud of his Swedish ancestry. (Later, he was to deliver the first paragraph of his acceptance speech in Stockholm for the 1951 Nobel Prize, in Swedish.) In Ishpeming his father would have been guaranteed employment for life as a machinist in the iron works, but he was never able to find permanent employment at his trade in California. Consequently, the family was very poor and Glenn early on earned his own spending money by taking paper routes, mowing lawns, and performing other odd jobs.

Glenn entered David Starr Jordan High School in the Watts section of Los Angeles in September 1925. He developed a special interest in chemistry and physics which he attributed to his inspiring high school chemistry and physics teacher, Dwight Logan Reid. Seaborg graduated as valedictorian of his class in 1929. At first he obtained work in a warehouse as a stevedore, but then found summer employment as a night laboratory assistant in the Firestone Tire and Rubber Co. to earn money for his freshman year at the University of California at Los Angeles (UCLA). UCLA was a tuition free public university and his earnings made it just barely possible for him to enter college in the depression year of 1929 because he could live at home and commute with friends some 20 miles to UCLA. He continued to work at a variety of odd jobs, but after getting a 99\% in the Quantitative Anyalysis exam in the Fall of 1930, he was hired to help in the labs and stockroom for 6 hours a week at 50 cents an hour. Then he was awarded a $\$ 150$ scholarship for 1931-1932, a handsome sum in those depression days. He decided to major in chemistry rather than physics because he felt it would provide him with more career opportunities if he were unable to find a position as a university teacher, his first choice for his future profession. During his last year at UCLA, he became particularly interested in the exciting new developments in nuclear physics and chemistry. After receiving his A. B. in Chemistry in 1934, he stayed on a fifth year 1933-1934 to take a number of courses in physics, which had just that year been started at the graduate (Master's Degree) level. 


\section{UC Berkeley: 1934-42}

Because graduate work had not yet been instituted in the Department of Chemistry at UCLA, Glenn went to Berkeley to pursue graduate work in chemistry, hoping to work near the great Professor Gilbert Newton Lewis, dean of the college of chemistry, as well as near the rising young nuclear physicist Ernest Orlando Lawrence, inventor of the cyclotron in the early 1930s and soon to be recipient of the Nobel Prize in Physics in 1939. Even at this early age, Glenn showed himself to be an amazingly good judge of professional talent!

Seaborg has described the atmosphere that existed at the University of California at Berkeley (UCB) when he entered as a graduate student in August 1934, as "exciting and glamorous" and he took formal courses in chemistry from many eminent professors. He earned his $\mathrm{Ph}$. D. in Chemistry in the spring of 1937 with a thesis on the inelastic scattering of fast neutrons. The U. S. was in the depth of the Depression and suitable positions were difficult to find, but he was soon asked by Lewis to stay on at Berkeley to serve as his personal research assistant and they published many papers together. Seaborg often expressed his admiration for Lewis as his great teacher and mentor. He regarded him as one of the scientific geniuses of our time who should have been awarded the Nobel Prize, but whose sometimes less than tactful interactions with other scientists ruined his chances.

During this period he collaborated with the physicist J. J. (Jack) Livingood to use the newly completed 37-Inch Cyclotron to produce and discover many new isotopes, including iodine-131, still widely used in nuclear medicine procedures. In 1938, he and Emilio Segré discovered technetium-99m, still the most widely used radioisotope for nuclear diagnostics. These experiences as a "radioisotope hunter" (Fig. 2-1) led eventually to the exploration of the transuranium elements which was to be his life-long research interest. Seaborg became an instructor at UCB in 1939 and in 1941 he was promoted to Assistant Professor.

During Seaborg's graduate years and later, he closely followed developments from Enrico Fermi's group in Italy in 1934 in bombarding uranium with neutrons and producing what they thought were transuranium elements, and the research of Otto Hahn, Lise Meitner, and Fritz Strassmann in Berlin on these so-called transuranium elements. When the exciting news of the discovery of nuclear fission by the Berlin Group came through to Berkeley by word of mouth, Edwin M. McMillan and Philip H. Abelson set out to study the fission process in bombardments of uranium with neutrons at the new 60-Inch Cyclotron at Berkeley. It had been put into operation under the tutelage of Ernest O. Lawrence in 1939 and made these experiments possible. Quite unexpectedly, McMillan and Abelson produced and identified the first "real" transuranium element. They chemically separated and identified it as element 93, for which they proposed the name neptunium. McMillan then began a search for the next heavier transuranium element (atomic number 94), but was soon called to wartime research at the Massachusetts 
Institute of Technology. Seaborg requested and received his permission to continue this search.

In February 1941, Seaborg led a team consisting of fellow instructor, Joseph W. Kennedy, and Seaborg's first graduate student, Arthur C. Wahl, in performing the first chemical separation and positive identification of plutonium. It was produced as the isotope plutonium-238 in deuteron bombardments of uranium. Soon after this, the new isotope plutonium-239 was produced and found to be highly fissionable with thermal neutrons. Recognizing the potential applications in nuclear weapons, Seaborg's group voluntarily withheld publication until after the end of World War II, but a secret report (Fig. 2-2) was sent to Washington, D. C. describing the chemical properties of elements 94 and 93 and suggesting the names plutonium $(\mathrm{Pu})$ and neptunium (Np) for them. Seaborg is shown in Fig. 2-3 in August 1941 with a Geiger-Muller counter in Gilman Hall where plutonium was separated and discovered. During the Fall of 1941 Seaborg also made another discovery. He began dating Helen Lucille Griggs, secretary to O. E. Lawrence, and they spent Christmas Day, 1941 together in San Francisco, one of the first times Glenn had not returned to spend Christmas with his parents in South Gate, California.

\section{University of Chicago- "Met" Lab: 1942-46}

These discoveries at Berkeley led to the U. S. decision to undertake a crash program to develop nuclear reactors to produce plutonium to be used in the U. S. atomic bomb project. In April 1942 Seaborg took leave of absence from UCB to go to the University of Chicago Metallurgical Laboratory ("Met Lab") to direct the work on the chemical extraction and purification of the plutonium produced in the reactors.

As soon as the decision was made in March 1942 that Seaborg should move to Chicago for work on the Plutonium Project, he proposed to Helen Griggs and she accepted. The understanding was that he would soon come back to Berkeley and they would be married. In June 1942 Seaborg returned from Chicago to Berkeley. After taking Helen to visit his parents in Southgate (Fig. 3-1), he persuaded her to return immediately with him to Chicago by train, promising her that they would be married en route. They disembarked from the train at Caliente, Nevada and were subsequently married at Pioche, Nevada on June 6, 1942, but not without some interesting "misadventures" which have been charmingly described by Helen Seaborg. (e.g., see Helen's account quoted by Seaborg in his preface, pp. 42-44, to the book, "The Transuranium People: The Inside Story" by D. C. Hoffman, A. Ghiorso, and G. T. Seaborg, Ref. 1.) Helen and Glenn's marriage was to last for more than 56 years and Seaborg often fondly referred to Helen as "his best discovery of all".

By 1944, the process chemistry for plutonium was essentially worked out, and Seaborg and his co-workers began attempts to produce and identify the next transuranium elements with atomic numbers 95 and 96 (americium and curium). They were unsuccessful until Seaborg came 
up with the "actinide" concept of heavy element electronic structure in which the 14 elements heavier than actinium (atomic number 89 ) are placed in the Periodic Table of Elements as a $5 f$ transition series under the lanthanide $4 f$ transition series. A new Periodic Table incorporating this concept was published in Chemical \& Engineering News in 1945 (Fig. 3-2). It was viewed as a "wild" hypothesis because at that time it was commonly believed that thorium, protactinium, uranium, neptunium, plutonium, and the following elements should be placed as the heaviest members of groups 4 through 10. But Seaborg postulated that the heavier actinides, like their lanthanide counterparts, would be extremely difficult to oxidize above the trivalent oxidation state. This concept was verified when chemical separations based on separating elements 95 and 96 as trivalent homologues of the lanthanides were successfully used in 1944 to separate and identify these new elements, subsequently named americium (Am) and curium (Cm).

\section{Back to Berkeley: 1946-51}

World War II formally ended in September 1945 and soon after that Glenn Seaborg returned from Chicago to Berkeley as full professor of chemistry, bringing some of his associates with him. The photo in Fig. 4-1 shows him together with E. O. Lawrence and J. Robert Oppenheimer in early 1946 at the controls of the Berkeley 184-Inch Cyclotron, just being converted from wartime use in isotope separation to its original purpose as a cyclotron for scientific purposes. By that time, Seaborg was also beginning to gain nationwide attention and was chosen by the U. S. Junior Chamber of Commerce as one of the 10 outstanding young men of 1947, along with another Californian, U. S. Representative Richard Nixon, who was later to be U. S. president from 1969-1974. They are shown in Fig. 4-2 with the other awardees and "Miss America" at the Award Ceremony in Chattanooga, Tennessee in January 1948.

In the following years up to 1958, Seaborg, S. G. Thompson, A. Ghiorso and co-workers, including many graduate students and postdoctoral fellows, went on to synthesize and identify the next six transuranium elements with atomic numbers 97 through 102. The first of these, berkelium (97) and californium (98), were produced at the Berkeley 60-Inch Cyclotron in 194950. Shortly thereafter, in 1951, Seaborg and McMillan (Fig. 4-3) shared the Nobel Prize in Chemistry for their research on the transuranium elements. Fig. 4-4 shows Helen and Glenn Seaborg dancing at the ball at the Nobel ceremony in Stockholm.

Seaborg's group at Berkeley, working together with scientists from Argonne National Laboratory and Los Alamos, was the first to separate and obtain evidence for the new elements 99 and 100, which had been most unexpectedly produced in the first thermonuclear device tested by the Los Alamos Scientific Laboratory in the South Pacific on November 1, 1952. The group proposed the names einsteinium and fermium for these elements in honor of the great scientists Albert Einstein and Enrico Fermi. Prof. Seaborg and coworkers then produced mendelevium 
(101) in 1956 using the 60-Inch Cyclotron and nobelium (102) in 1958 using the Heavy Ion Linear Accelerator (HILAC) at the Berkeley Radiation Laboratory at Berkeley. According to the actinide hypothesis, it was expected that nobelium should have a relatively stable $2+$ state by analogy with ytterbium which can be reduced from $3+$ to $2+$ with strong reducing agents. It was found that not only is the $2+$ state of nobelium achievable, it is the most stable oxidation state of nobelium in aqueous solution.

During this period (1946-1958), Seaborg served as director of the Nuclear Chemistry Division and became an associate director of the Berkeley Radiation Laboratory in 1954. In addition to the research on the production and chemical properties of the transuranium elements, dozens of new isotopes and much of the data on alpha-particle radioactivity and nuclear energy levels needed for the evolution of modern theories of nuclear structure were obtained.

Seaborg began to broaden his horizons to national public service and served on the first General Advisory Committee to the Atomic Energy Committee from 1947 to 1950. Members of the President's Scientific Advisory Council are shown in Fig. 4-5 with President Dwight Eisenhower in December 1960. Seaborg was appointed Chancellor of UCB in 1958 and served until 1961 when president-elect John F. Kennedy asked him to chair the U. S. Atomic Energy Commission (AEC).

\section{Washington, DC: 1961-71}

Seaborg's tenure as Chairman of the AEC from 1961 to 1971 was longer than that of any other Chairman and spanned the presidencies of John F. Kennedy (1961-1963), Lyndon B. Johnson (1963-1968), and Richard M. Nixon (1969-1974). Under Seaborg's guidance, the AEC played a significant role in the negotiation of the Non-Proliferation Treaty and took the lead in instituting national and international safeguards to assure that nuclear materials were not diverted from peaceful uses to weapons purposes. He was a strong advocate of a Comprehensive Test Ban Treaty. Under Kennedy's presidency, Seaborg led negotiations resulting in the limited nuclear test ban treaty (LTBT) prohibiting the testing of nuclear devices (Fig. 5-1) in the atmosphere or under the sea, which was approved by the U. S. Senate in August, 1963. Under Johnson, strategic arms limitation treaty (SALT) talks were begun. The nonproliferation treaty (NPT) was negotiated and signed in 1968, and then ratified in the Senate in March, 1969 under Nixon.

Glenn and Helen and their six children are shown in Fig. 5-2 at their Washington D. C. home in August, 1964. Helen was his constant companion and advisor and accompanied him on most of his many trips, faithfully attending the scientific and other symposia in which he was involved. 
Seaborg was instrumental in implementing awards to scientists in the U. S. and abroad. When Lyndon Johnson became president in late 1963 after the assassination of John Kennedy, Seaborg encouraged him to proceed with the presentation of the Fermi Award of the U. S. AEC to J. Robert Oppenheimer in January 1964 (Fig. 5-3), in spite of the strenuous disapproval of many members of Congress. (Oppenheimer's security clearance had been suspended in 1954 after he had been deemed a security risk.) In 1966, the Fermi Award went jointly as suggested by Seaborg to three non-U. S. citizens: Lise Meitner, Otto Hahn, and Fritz Strassman for their "independent and collaborative contributions" to the discovery of nuclear fission. Seaborg went to Cambridge in October 1966 to present the Award to Lise Meitner in person (Fig. 5-4) as she was not physically able to attend the original Award Ceremony in Vienna, Austria in August of that year.

Seaborg strongly recommended to President Nixon that special one-time Atomic Pioneer Awards be presented to Vannevar Bush, James B. Conant, and General Leslie R. Groves for their service in running the war-time Manhattan project to build nuclear weapons. Nixon accepted this recommendation and the awards were presented in February 1970 (Fig. 5-5).

As AEC Chairman, Seaborg strongly supported the use of nuclear energy as a source of electricity, and led delegations to some 63 countries promoting the peaceful uses of atomic energy. He also continued his interest in transuranium element research, and the National Transplutonium Production Program was established at the High Flux Isotope Reactor (HFIR) which was commissioned at the Oak Ridge National Laboratory in the mid-1960s. The HFIR and the associated transuranium processing facility (TRU) were essential to the production of rare heavy element isotopes to be used in the synthesis of new heavy elements and in heat sources for space exploration. Other radioactive isotopes for applications in biology, nuclear medicine, and industry were produced. During his tenure the support for basic research in the physical sciences, biology, and medicine nearly doubled.

\section{Berkeley: 1971-99}

Seaborg returned to Berkeley in 1971 as University Professor of Chemistry, a prestigious appointment by the Regents of the University of California which made him a professor of chemistry at all the UC campuses. He continued to serve as an informal scientific advisor to successive presidents and many governmental bodies. He is shown (Fig. 6-1) introducing VicePresident Gerald Ford at the World Future Society Conference in Washington, D. C. in 1974.

He taught regularly until 1979, supervising the $\mathrm{Ph}$. D. research of more than 65 students in all. He is shown in Fig. 6-2 as a member of the team that discovered element 106 at LBNL in 1974, later to be named seaborgium $(\mathrm{Sg})$ in his honor. 
In 1982, he became the first director of the Lawrence Hall of Science, which he founded. He served as Associate Director-at-Large of the Lawrence Berkeley National Laboratory until his death in 1999. He was active in many international organizations for fostering the application of chemistry to world economic, social, and scientific needs.

Seaborg maintained and even escalated his interest in better education in science and mathematics at all levels and served on many federal and state committees. President Reagan appointed him to be a member of the Commission on Excellence in Education (NCEE) and they are shown together in Fig. 6-3 on the occasion of the presentation of the report "A Nation at Risk" in April 1983. In 1989, Seaborg and the current Secretary of Energy James Watkins hosted a Mathematics/Science Action Conference at the Lawrence Hall of Science (Fig. 6-4) that again called for a revitalization of science education in the U. S. In 1989, Seaborg was asked to brief President George A. Bush on the "cold fusion" phenomenon (Fig. 6-5) and received the Presidential National Medal of Science from him in 1991.

In addition to the Nobel Prize in 1951, Seaborg received a host of other awards. The name "seaborgium" for element 106 was officially approved by IUPAC in 1997, an honor which Seaborg said he cherished more highly than the Nobel Prize. A photo of Seaborg is shown in Fig. 6-6 on 18 October, 1997, proclaimed Glenn Seaborg Day by the city of Berkeley, California to recognize the naming of element 106 as "seaborgium".

He received honorary degrees from some fifty universities, was elected to a dozen foreign national academies of science, held more than 40 patents, authored more than 500 scientific articles and numerous books, including editing his journals, which he faithfully kept throughout his career. These formed the basis for a number of books, including an autobiography [5] published in 1998 entitled, "A Chemist in the White House: From the Manhattan Project to the End of the Cold War". Seaborg is listed in the Guiness Book of World Records for having the longest entry in "Who's Who in America"!

I have often tried to figure out why and how Glenn Seaborg accomplished so much - how he managed to "do it all" and contribute to so many fields - sustaining a high level of achievement right up to the very end of his life. Certainly a strong factor was his wife Helen who was his ultimate confidant, "advisor", and in later years his almost constant traveling companion. A portrait of them taken in 1996 is shown in Fig. 6-7.

It is true that Glenn was a master administrator of science and knew how to delegate, and that he worked extremely hard and never gave up, but in truth, many people do that! But, in addition, Glenn had a rare ability, which in current jargon, might be characterized as being able to be a "parallel" processor. He could keep track of a multitude of very important projects all at once, perhaps due to his fabulous memory, reinforced by his lifelong habit of recording everything in his famous journals. Not only was he was able to access this wealth of 
information, but even more importantly, he was able to apply it as required. His organizational skills were legendary and as long-time collaborator and friend Albert Ghiorso says, "He always kept his eye on the ball and had a knack for doing the right thing at the right time."

Glenn continued to travel and lecture widely in the U. S. and abroad until his death. $\mathrm{He}$ maintained an active interest in issues such as the first studies of the chemical properties of the transactinide elements (atomic number $>103$ ), the search for superheavy elements, science education, the nuclear test ban treaty, nuclear non-proliferation and the use of nuclear power, as well as hiking and sports. He and Helen laid out an interconnected network of 12-mile trails in the East Bay Hills above Berkeley that extended to the California-Nevada border, forming a link in a cross-country trek of the American Hiking Society. Football was his favorite spectator sport and he liked to point out that during his tenure as Chancellor the Berkeley football team went to the Rose Bowl!

Our final collaborative effort, together with Albert Ghiorso, resulted in the book entitled “The Transuranium People: The Inside Story", published [4] in early 2000. Of course, in typical fashion, he had his sections completed long ahead of time with appropriate figures and pictures, but $\mathrm{Al}$ and I worked long and hard to get all our pictures in and have him read our final texts. Somehow I was obsessed with getting this project completed and sent to the publisher before we left for the August 1998 ACS national meeting in Boston where he suffered the stroke and fall on August 24, 1998 that ultimately led to his death on Thursday evening of February 2, 1999. After the historical session on chemistry of the Manhattan Project on Monday morning, August 24, 1998, we had a photo taken together that I believe is one of the last photos of him (Fig. 6-8).

One of our great regrets is that he did not live to participate in the joy of discovery of the new superheavy elements 118, 116, and 114 by our Heavy Element Nuclear and Radiochemistry Group in May 1999 [6] and the reports [7,8] of element 114 by the Dubna/Livermore and Dubna/international groups. Fig. 6-9 shows an updated version of Seaborg's periodic table that also shows the position he proposed for the "superactinide" series.

In spite of his legendary accomplishments, Glenn Seaborg always had time for family members, colleagues, students, and even non-scientists who wanted to visit with him. We have lost a treasured advisor, colleague, mentor, resource, and friend. But he will live on through his prolific writings and in the cherished memories of the multitude of students, scientists, colleagues, and lay people that he touched in his long and productive life.

I would like to close my remarks in his memory with an excerpt from the statement he delivered upon being appointed Chancellor of the University of California, Berkeley in 1958. It is my favorite quote and an appropriate ending for these remarks, as well as an opening for the rest of the presentations to follow. 
"There is a beauty in discovery. There is mathematics in music, a kinship of science and poetry in the description of nature, and exquisite form in a molecule. Attempts to place different disciplines in different camps are revealed as artificial in the face of the unity of knowledge. All literate men are sustained by the philosopher, the historian, the political analyst, the economist, the scientist, the poet, the artisan and the musician."

\section{REFERENCES}

1. Journals of Glenn T. Seaborg: Published in 8 volumes spanning the years from 1927-1976.

2. The Plutonium Story: The Journals of Professor Glenn T. Seaborg, 1939-1946 (R. L. Kathren, J. B. Gough, Gary T. Benefiel, eds.) Battelle Press, Columbus, Ohio 1994.

3. Modern Alchemy: The Selected Papers of Glenn T. Seaborg. (G. T. Seaborg, ed.) World Scientific Publishing Co. Pte. Ltd., Singapore 1994.

4. Hoffman, D. C., Ghiorso, A., Seaborg, G. T.: The Transuranium People: The Inside Story. World Scientific Publishing Co. LTD, Singapore, 2000.

5. Seaborg, Glenn T.: A Chemist in the White House: From the Manhattan Project to the End of the Cold War, American Chemical Society, Washington, DC, 1998.

6. Ninov, V. et al.: Phys. Rev. Lett. 83, 1104 (1999).

7. Oganessian, Yu. et al.: Nature 400, 242 (1999).

8. Oganessian, Yu. et al.: Phys. Rev. Lett. 83, 3154 (1999).

\section{$\underline{\text { INTERNET CITATIONS }}$}

E. O. Lawrence Berkeley National Laboratory, One Cyclotron Road, Berkeley, CA 94720.

Web page http://seaborg.lbl.gov; http://sheiks.lbl.gov

The Seaborg Center, Northern Michigan University, Marquette, MI 49855-5394.

Web page http://seaborg.nmu.edu 